\title{
Application of Drucker-Prager Plasticity Model for Concrete Confined with Fiber Reinforced Cementitious Mortar (FRCM)
}

\author{
Ali Hadi Adheem ${ }^{1}$, Majid M.A. Kadhim ${ }^{2 *}$, Akram Jawdhari ${ }^{3}$, Mohammed J. Altaee ${ }^{4}$ \\ \{inkr.ali@atu.edu.iq ${ }^{1}$, majid.mohammed@uobabylon.edu.iq², akram.hassan@uky.edu³ \\ mohammed.altaee@uobabylon.edu.iq $\left.{ }^{4}\right\}$
}

\begin{abstract}
Kerbala Technical Institute, Al-Furat Al-Awsat Technical University, 56001 Kerbala, Iraq ${ }^{1}$, College of Engineering, University of Babylon, Hilla, Iraq ${ }^{2}$, Department of Construction and Projects, University of Babylon, Hilla, Iraq ${ }^{3}$,Environmental Research and Studies Centre, University of Babylon, Hilla, Iraq ${ }^{4}$.
\end{abstract}

\begin{abstract}
Wrapping concrete columns with fiber reinforced polymer (FRP) jackets can result in a significant increase of compressive strength and ductility, and can mitigate deterioration due to aging, chemical attacks, overloading, and seismic activity. Cementitious mortar has recently been used as a binder for FRP reinforcement, leading to a sustainable and environmental friendly construction, in lieu of synthetic binders (e.g. epoxy) which suffer from a number of drawbacks. The system is termed fiber reinforced cementitious mortar (FRCM) and can be used to repair concrete in shear and flexure, or in columns confinement. In this study, a comprehensive three-dimensional (3D) finite element (FE) model was developed to study the behavior of concrete confined with FRCM jackets. The model incorporated a Drucker-Prager (DP) plasticity law to simulate effects of confinement on concrete core, a composite damage mechanics (CDM) criteria to predict rupture of FRP mesh, and a concrete plasticity model to simulate cracking of the cementitious mortar. The model predictions were compared with test results of 11 FRCMconfined concrete cylinders comprising various dimensions, FRCM layers, and concrete strengths. The model was able to accurately predict the peak compressive strength of confined concrete $\left(f_{c c}\right)$, peak axial strain $\left(\varepsilon_{c c}\right)$, and entire stress-strain curve in addition to the failure mode of each analyzed specimen. Calibrated model will enable examination of several geometric and material parameters, and assist in establishing an accurate confinement model for FRCM-confined concrete.
\end{abstract}

Keywords: FRCM, confinement, columns, finite element, drucker prager, plasticity.

\section{Introduction}

Fiber-reinforced polymer (FRP) systems have become widely used in concrete construction with applications ranging from reinforcement of new members to repair and strengthening of old ones. Laboratory tests showed that confining of reinforced concrete (RC) columns with FRP sheets and plates can increase compressive strength and ductility, as well as the ability to carry more vertical and lateral loads [1-4]. Although offering many outcomes ex. high strength, lightweight, ease and speed of application, and resistance to corrosion, FRPs still have some limitations particularly those related to the use of synthetic adhesives (e.g. epoxy), including degradation of bond and stiffness under elevated temperature, difficulty in application on 
wet surfaces, poor performance under fire, low compatibility with the substrate, and moisture impermeability $[5,6]$.

In response to these drawbacks, inorganic binders, such as from cement or geopolymer mortars, have been implemented to provide a sustainable and environmentally-friendly adhesive. The new system is known in literature as textile reinforced mortar (TRM) or fiber reinforced cementitious mortar (FRCM), and it consists of orthogonal FRP fabric meshes or grids, embedded in the mortar [5-10]. FRCM technique has been successfully used in strengthening $\mathrm{RC}$ beams in flexure, shear and torsional loading cases [7, 11, 12]. It was also investigated for the case of strengthening RC columns $[6,8,9]$ and plain stub columns $[5,10]$.

Application of FRCM technique for stub columns demonstrated potential enhancement to concrete strength as a result of confinement. Several studies have confirmed that the use of FRCM on concrete compression members can significantly improve stiffness, strength and ductility [5]. Recently, Trapko [10] conducted an experimental study on concrete cylinders confined by either FRCM jackets or conventional FRP sheets, considering the effects of two parameters; temperature and number of transverse reinforcement layers. The FRCM jacket consisted of a polyparaphenylene benzobisoxazole (PBO) fiber mesh embedded in cementbased mortar. Both systems were able to increase the compressive strength and modulus of elasticity, but FRCM showed a superior performance under elevated temperature. The strength and stiffness increased proportionally with number of CFRP or PBO mesh layers.

Ombres [5] conducted research on concrete cylinders reinforced with multi-layers of PBO fibres embedded in an inorganic matrix to evaluate the efficiency of the FRCM system. The effect of fibre reinforcement ratio and fibre orientation was investigated. The results showed that this technology has a strong potential to raise the restricted concrete's peak strength and axial strain. Excessive dilatation caused concrete to bulge, which was followed by cracking in the mortar and debonding at the fabric and mortar interface.

The confinement of low-strength concrete with FRCM composites was also investigated by Gonzalez-Libreros, et al. [13], considering several parameters including: types of fibers, using carbon or glass; cross-section shape, using circular, square and rectangular; specimen size for cylinders with a constant slenderness ratio $(\mathrm{h} / \mathrm{d})$ of 2 , where $\mathrm{h}$ is height and $\mathrm{d}$ is diameter; and effects of a pre-existing damage. The experimental results showed that the strength and ductility gains depend on composite type; cross-section geometry and specimen dimensions. In addition, it was found that the damaged specimens can achieve full strength recovery when carbon-FRCM system was applied.

With FRCM system proving to be a viable option for concrete confinement, the technical database needs to be expanded beyond the few available experimental and analytical studies, in order to bridge the gap in knowledge, examine the effects of more parameters, and finally establish an accurate confinement model similar to that used in conventional FRP sheets. Although multiple studies implemented finite element (FE) modeling technique in studying the effects of FRCM system in enhancing shear, flexure, and torsion behavior of concrete, very few focused on confined axial members. This study goal to establish a robust 3D FE model for FRCM-confined concrete. The calibrated model is intended to be used in a large parametric analysis on effects of several variables such as fiber properties and orientation, number of layers, thickness of fiber mesh, cross-section type, slenderness ratio, corner radius of square sections, and concrete compressive strength. The main objective is to provide a larger population of investigated parameters in order to enable an accurate stress-strain confinement scheme for this new system. 


\section{Experimental Summary}

The model results were compared with those from experimental tests on standard concrete cylinders confined with FRCM jackets. Eleven specimens, 3 from a study by Trapko [10] and 8 from a study by Ombres [5], were selected as a validation data and were chosen because they represented a wide range for geometric and material variables and contained all inputs needed for modeling, such as the stress-strain curve. The cylinders from Trapko [10] were $300 \mathrm{~mm}$ in height $(\mathrm{H})$ and $113 \mathrm{~mm}$ in diameter (D); while those from Ombres [5] had an H of 290-295 mm, and D of 152-153 mm. Different number of FRCM layers, ranging from 1 to 4, were used, resulting in multiple confinement ratios. The FRCM system was applied by dampening the cylinder's surface and applying an initial coat of mortar, followed by wrapping with the fiber mesh, and then covering with a final coat of mortar. The average total thickness of the mortar ranges from 3 to $5 \mathrm{~mm}$, per one FRCM layer. In all specimens, the fiber mesh within FRCM system was applied by orienting the main fibers parallel to the hoop direction. Compressive strength of unconfined concrete (fco) ranged from 15.4 to $29.3 \mathrm{MPa}$. Table. 1 lists the geometrical and material properties of the cylinder tests, along with key results and comparisons between test and FE model. The mechanical properties of PBO-fiber mesh and the mortar are listed in in Table, 2, as reported in Trapko [10] and Ombres [5].

Table 1. Key experimental and FE results for FRCM-constrained cylinders.

\begin{tabular}{|c|c|c|c|c|c|c|c|c|c|c|c|}
\hline \multirow[t]{2}{*}{ Label } & \multirow{2}{*}{$\begin{array}{c}D \\
\mathrm{~mm}\end{array}$} & \multirow{2}{*}{$\begin{array}{c}H \\
\mathrm{~mm}\end{array}$} & \multirow{2}{*}{$n$} & \multirow{2}{*}{$\begin{array}{c}t_{f} \\
(\mathrm{~mm})\end{array}$} & \multirow{2}{*}{$\begin{array}{c}f_{c o} \\
\mathrm{MPa})\end{array}$} & \multicolumn{2}{|c|}{$f_{c c}(\mathrm{MPa})$} & \multirow{2}{*}{$\begin{array}{l}\text { Exp. } \\
\text { /FE }\end{array}$} & \multicolumn{2}{|c|}{$\varepsilon_{c c}$} & \multirow{2}{*}{$\begin{array}{c}\text { Exp./ } \\
\text { FE }\end{array}$} \\
\hline & & & & & & Exp. & $\mathrm{FE}$ & & Exp. & $\mathrm{FE}$ & \\
\hline M1-1 & 113 & 300 & 1 & 0.0455 & 22.60 & 32.66 & 33.39 & 0.98 & 0.0070 & 0.0068 & 1.03 \\
\hline M2-1 & 113 & 300 & 2 & 0.0455 & 22.60 & 42.48 & 44.50 & 0.95 & 0.0121 & 0.0131 & 0.92 \\
\hline M3-1 & 113 & 300 & 3 & 0.0455 & 22.60 & 55.80 & 57.78 & 0.97 & 0.0171 & 0.0211 & 0.81 \\
\hline CRP1-I & 152 & 290 & 1 & 0.0455 & 15.40 & 24.69 & 22.73 & 1.09 & 0.0115 & 0.0134 & 0.86 \\
\hline CRP2-I & 152 & 290 & 2 & 0.0455 & 15.40 & 35.00 & 34.11 & 1.03 & 0.0200 & 0.0253 & 0.79 \\
\hline CRP3-I & 152 & 290 & 3 & 0.0455 & 15.40 & 41.45 & 41.04 & 1.01 & 0.0290 & 0.0274 & 1.06 \\
\hline CRP4-I & 152 & 290 & 4 & 0.0455 & 15.40 & 49.24 & 48.01 & 1.03 & 0.0264 & 0.0289 & 0.91 \\
\hline CRP1-II & 153 & 294 & 1 & 0.0455 & 29.26 & 43.55 & 39.14 & 1.11 & 0.0080 & 0.0147 & 0.54 \\
\hline CRP2-II & 153 & 292 & 2 & 0.0455 & 29.26 & 47.00 & 44.83 & 1.05 & 0.0148 & 0.0168 & 0.88 \\
\hline CRP3-II & 153 & 292 & 3 & 0.0455 & 29.26 & 56.60 & 53.27 & 1.06 & 0.0193 & 0.0215 & 0.90 \\
\hline CRP4-II & 153 & 295 & 4 & 0.0455 & 29.26 & 56.23 & 55.88 & 1.01 & 0.0216 & 0.0217 & 1.00 \\
\hline
\end{tabular}

Note: $D=$ diameter; $H=$ height; $t_{f}=$ equivalent fiber thickness in one FRCM layer; $\mathrm{n}=$ number of fabric meshes; $f_{c o}=$ compressive strength of unconfined specimens; $f_{c c}=$ peak compressive strength of confined concrete; $\varepsilon_{c c}=$ peak axial strain of confined concrete.

\section{Finite Element Analysis}

The FE models for FRCM-confined concrete cylinders were prepared in general purpose software ANSYS v 17.2 [14], using a nonlinear three-dimensional (3D) modeling approach. The concrete core is represented by an 8-node brick element SOLID185 (Fig. 1), having three translational degrees of freedom (DOFs) in $\mathrm{x}, \mathrm{y}$, and $\mathrm{z}$ orthogonal Cartesian directions. This 
element can be used to develop non-linear model ex. plasticity, stress stiffening, large deformation, and large strain [14]. Two cylindrical steel plates (Fig. 1), each is $10 \mathrm{~mm}$ thick, were added at the top and bottom surfaces of the cylinder to minimize stress concentration within the concrete, and were also modeled by SOLID185.

Table 2. Mechanical and geometrical properties of FRCM strengthening system.

\begin{tabular}{lcccccc} 
No. & Reference & $E_{f}(\mathrm{GPa})$ & $f_{f u}(\mathrm{MPa})$ & $\varepsilon_{f u}$ & $E_{m}(\mathrm{GPa})$ & $f_{c m}(\mathrm{MPa})$ \\
\hline 1 & Trapko [10] & 270 & 5270 & 2.15 & 6.0 & 29.0 \\
2 & Ombres [5] & 270 & 5800 & 2.00 & 6.1 & 30.4
\end{tabular}

Note: $E_{f}=$ elastic modulus of PBO mesh; $f_{f u}=$ ultimate tensile strength of PBO mesh; $\varepsilon f u=$ failure strain of PBO mesh; $E_{m}=$ elastic modulus of mortar; $f_{\mathrm{cm}}=$ compressive strength of mortar.

The mortar layer was modelled as a distinct solid portion with a thickness (tm) as reported from the tests in order to replicate mortar cracking, which was a frequently found failure mode in FRCM-confined concrete columns. In addition, the mortar is believed to aid confinement, especially prior to breaking. The mortar was modelled using SOLID65, an 8-node brick element with 3 translational DOFs. Because of its unique capacity to portray concrete and the incorporation of cracking and crushing algorithms [14]. the element was chosen. Shell element SHELL181 was used to simulate the fibre mesh in the FRCM system (Fig. 1). The element has 4 nodes with six DOFs (three translational and three rotational), and is able to resist both membrane and bending forces [14]. In order to simplify the modeling process, the fiber mesh in FRCM system which is an open grid of orthogonal fiber strips, was replaced by a continuous fabric with thicknesses in the orthogonal directions determined from equating the axial stiffness of the grid to that of the fabric $[11,12]$. The fibre mesh and mortar were assumed to have a full bond, which was numerically idealised by establishing a same mesh size for both portions and then merging the duplicate nodes. Multiple FRCM layers were replaced with one central fabric layer embedded in one mortar layer if more than one FRCM layer was used. The idealised fabric (ta) and mortar (tm) thicknesses are simply multiplied by the number of layers in the multi-layer confinimeent system. 

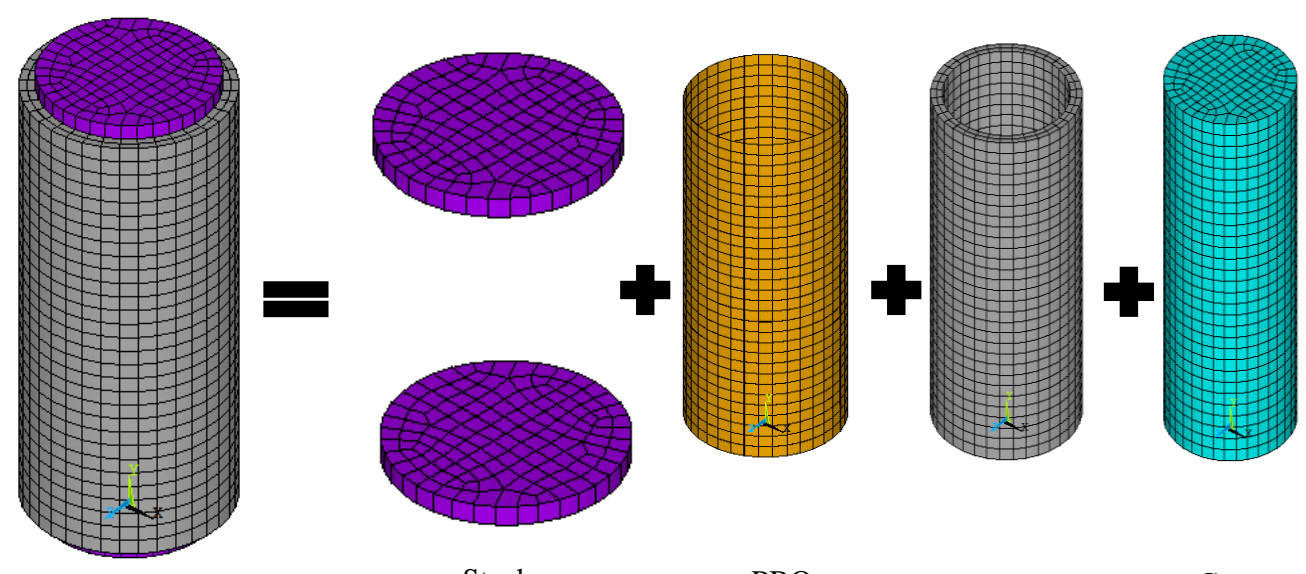

$\begin{array}{cc}\text { Steel } & \text { PBO } \\ \text { plates } & \text { mesh }\end{array}$

Mortar

Concrete cylinder

Figure 1. Modelling of concrete cylinder confined with FRCM system.

\section{Material modelling}

The DP concrete model $[15,16]$, which is a plasticity model based on the premise of elasticperfectly plastic response, has been widely used in modelling concrete confined with FRP sheets and jackets. The model accounts for concrete dilatation under axial compression and has produced positive results in several numerical studies (Ghanem, 2016). Traditional DP models, on the other hand, ignore the substantial difference in concrete's compressive and tensile strengths, and are unable to account for softening after cracking or crushing [14].

A modified Drucker-Prager (DP) concrete model is included in ANSYS version 17.2, which includes a separate failure criterion for tension and compression, nonlinear stress-strain response in compression, and several hardening/softening mechanisms including linear, exponential, piece-wise linear, and fracture energy [14]. The modified DP model was used to simulate the confined concrete cylinders investigated in this study. The DP model is not readily available in ANSYS library of materials and can't be inputted from the typical graphical user interface (GUI). Therefore, a command subroutine was used to implement the model within ANSYS environment. The elastic modulus of concrete $(\mathrm{Ec})$ and Poisson's ratio are also required in the DP model (v). Ec was determined from ACI-318-14 [17] equation, while $\mathrm{v}$ was assumed to be $0.2[18]$.

The mortar was simulated by a nonlinear model suggested by [19], and widely used in research for grout and concrete materials [18]. The model utilizes a five-parameter failure criteria proposed by [20], and considers cracking and crushing failures. Material properties required to develop the model were taken from Trapko (2014b) [10] and (Ombres 2014) [5] and were reported in Table. 2. Both the open and closed shear fracture parameters were set to 0.3, with $\mathrm{v}$ set to 0.2 . The steel plates that were added were modelled as a linear elastic material with a s modulus of elasticity (Es) of $200 \mathrm{GPa}$ and a Poisson's ratio (v) of 0.3 .

Until it failed, the fabric was modelled as an orthotropic elastic material. As described in the experimental experiments, Table 2 summarises some of the mechanical qualities required for the model. Other material parameters, such as transverse elastic moduli, shear moduli, and 
Poisson's ratios, were not provided in the tests and were instead derived from [18]. In this investigation, a composite damage mechanics (CDM) model available in ANSYS was used to explicitly simulate fabric rupture. The rupture failure initiated when the stress exceeds the tensile strength, f fu specified in Table. 2. After failure initiation, the stiffness drops to a small value representing the brittle nature of fiber mesh failure. More information on the CDM are detailed in [18][21].

\section{Validation of FE model}

The findings of the numerical model were compared with the known practical results to verify the accuracy of the FE model $[5,10]$. The axial stress-strain curve, maximum stress, and failure pattern were all compared. Various mesh sizes were investigated in order to find one that strikes a reasonable balance between computational effort and accuracy. When compared to smaller meshes, a mesh with an element side length of $10 \mathrm{~mm}$ for all parts (concrete, cloth, and mortar) was determined to be sufficient and produced a maximum stress divergence of less than $1 \%$.

\subsection{Peak strength and axial strain}

The maximum value of stress throughout the test is represented by the peak compressive strength of confined concrete (fcc). Table 1 shows the peak compressive strength values and their related peak strain values. The amount of PBO mesh layers has a significant impact on peak strength values, as can be shown in this table. This pattern holds true for both experimental and FE results.. It can also be concluded from this table that the maximum divergence between the results obtained from the experimental and FE was less than $11 \%$. With regard to peak axial strain $(\varepsilon \mathrm{cc})$, the FE model can also predict the experimental values of peak strain in good agreement apart from specimen CRP1-II. The numerical divergence for this specimen is because it experienced an early peaking in stress in the experiment, which was significantly different from the rest of specimens.

\subsection{Stress strain response}

Figures 2 and 3 show the degree of convergence between test and computed results. It indicated that the FE model has the ability to simulate laboratory tests with a high degree of accuracy. It can also be seen that the overall response in terms of stress-strain curves obtained experimentally are well predicted by the FE model. The stress-strain curves for most specimens are similar in shape for both experimental and FE data, indicating a bilinear hardening trend. The slope of the second line (E2) represents confinement effects and is controlled by a variety of factors such as the jacket material, thickness, and number of layers, among others. E2 grows proportionally with the number of applied FRCM layers, as shown in the figures. This tendency can be seen in both experimental and FE findings, indicating that the FE model can accurately predict the behaviour of concrete jacketed with FRCM systems. 


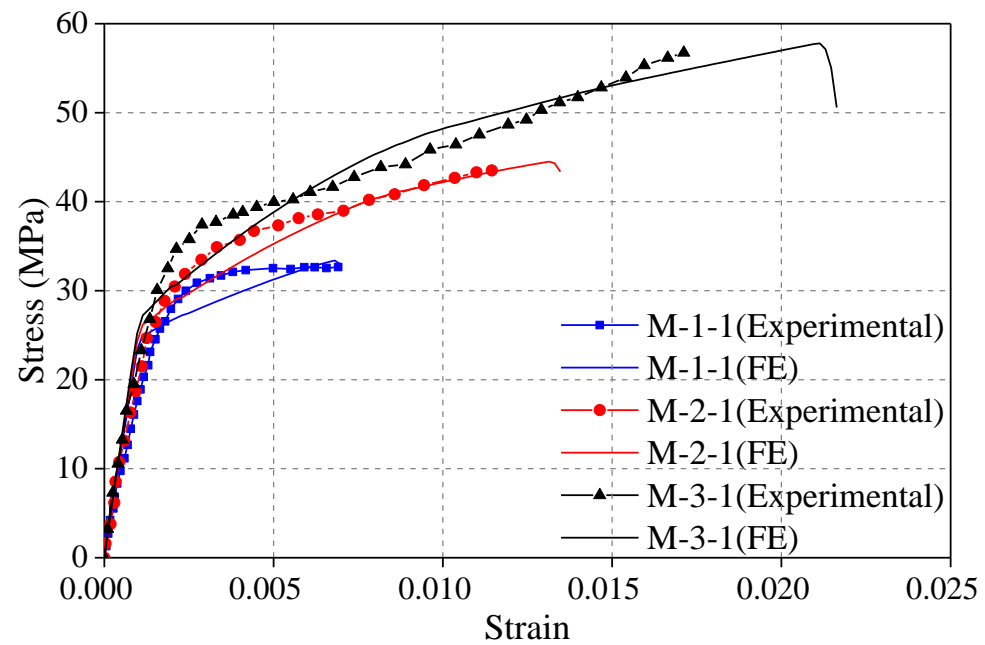

Figure 2. Comparison between stress-strain curves of FE results and concrete cylinders [10].
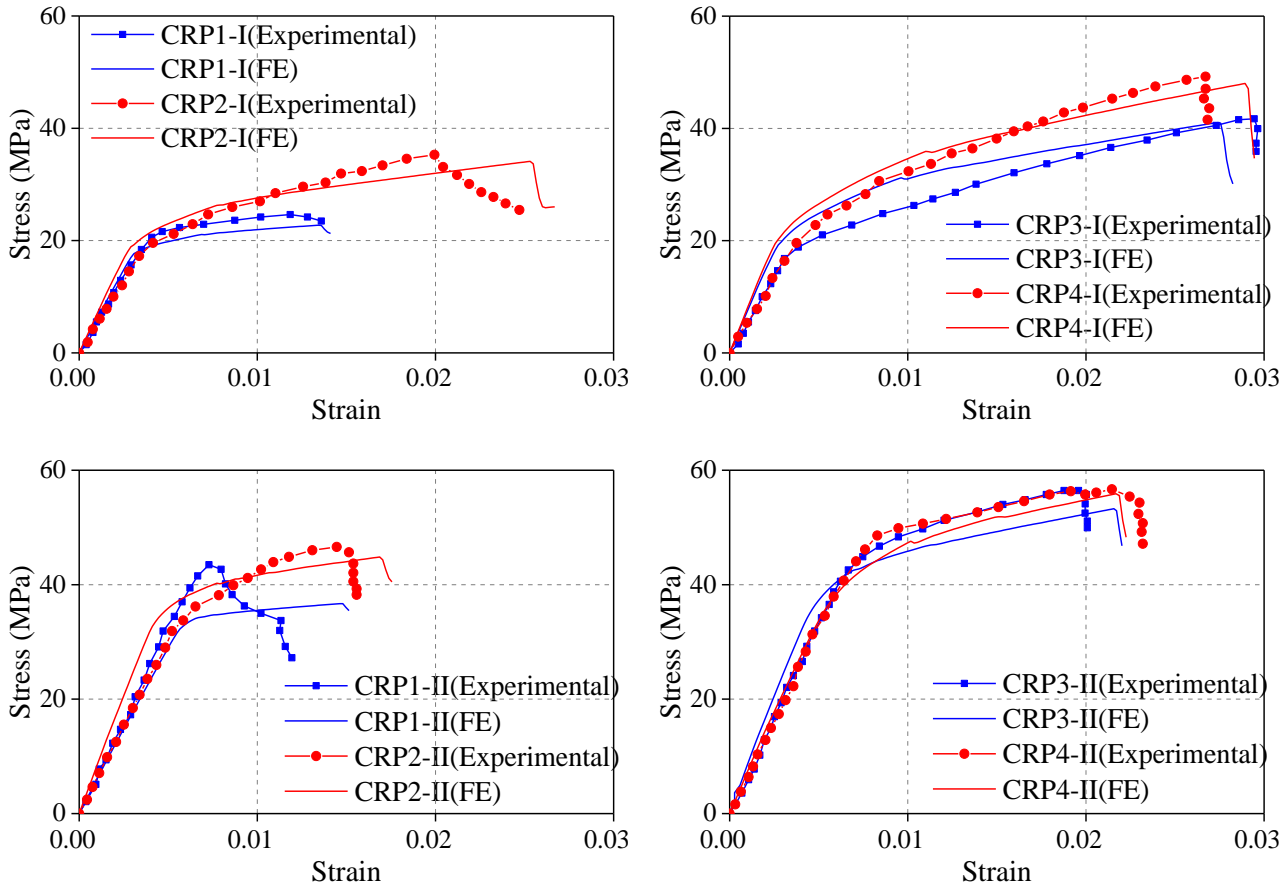

Figure 3. Comparison of experimental [5] and FE results on stress-strain curves of constrained concrete cylinders.

\subsection{Failure modes}

The FRCM jacket burst in the hoop direction, which was the most common failure mode of FRCM-jacketed concrete cylinders that preceded by extensive cracking in the mortar layer (Fig. 4). In the FE model, the failure criteria for PBO mesh was inputted to ensure that accurate results 
can be obtained from this model. Figure 4 shows the failure modes obtained from the FE model and the practical tests of both sets of experiments [5, 9]. The failure mode was reasonably captured by the FE model, as shown in this diagram (PBO mesh rupture). Based on the foregoing explanation, it can be inferred that the FE model is capable of capturing the full behaviour of the FRCM-reinforced concrete cylinders. This result was reached based on a high level of agreement between the FE model and the matching experimental data.

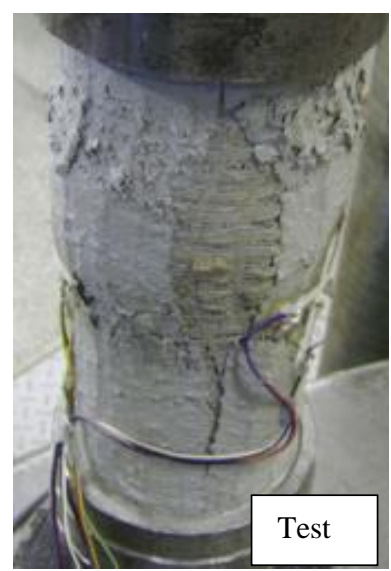

(a)

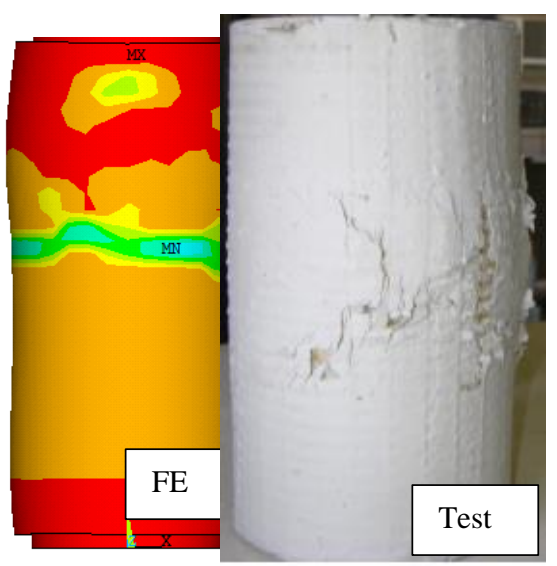

(b)

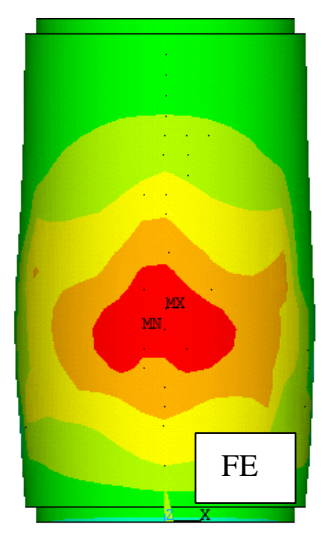

(b)

Figure 4. Comparison of failure modes for FE results and experimental obtained from (a) Trapko [10] and (b) Ombres [5].

\section{Conclusions}

The stress-strain behaviour of concrete axial members constrained by a fiber-reinforced cementitious mortar (FRCM) system was investigated using a thorough three-dimensional finite element (FE) model created in this study. The concrete core was modelled using a modified Druker Prager (DP) model, which included a separate failure criterion for tension and compression, nonlinear stress-strain response in compression, and multiple hardening/softening parameters. Mortar cracking and fiber mesh rupture failures were explicitly simulated, using proper element and material models.

The results of 11 tests on FRCM-confined concrete cylinders, featuring varying material and geometric properties as well as different confinement layers. Comparisons in terms of the axial stress-strain curve, maximum stress (f cc) of confined concrete, and failure pattern, showed the model's ability to reproduce the behavior of tested specimens. The model's divergence for (f cc) was less than $11 \%$. More importantly, the model was capable of capturing the effects of different confinement levels obtained from using various numbers of FRCM jackets. Following validation, the model will be utilised to do a broad parametric analysis on the effects of various critical parameters, as well as to create an accurate analytical stress-strain confinement model for concrete wrapped with the FRCM system.

\section{References}


[1] Nanni, A.Bradford, N.M., FRP jacketed concrete under uniaxial compression. Construction and Building Materials, 1995. 9(2): p. 115-124.

[2] Berthet, J., Ferrier, E. and Hamelin, P., Compressive behavior of concrete externally confined by composite jackets. Part A: experimental study. Construction and Building Materials, 2005. 19(3): p. 223-232.

[3] Kadhim, M.M.A., Nonlinear FE analysis of reinforced HS concrete continuous beam strengthened with CFRP sheet. International Journal on Advanced Science, Engineering and Information Technology, 2011. 1(6): p. 597-601.

[4] Realfonzo, R.Napoli, A., Concrete confined by FRP systems: confinement efficiency and design strength models. Composites Part B: Engineering, 2011. 42(4): p. 736-755.

[5] Ombres, L., Concrete confinement with a cement based high strength composite material. Composite Structures, 2014. 109: p. 294-304.

[6] Ombres, L.Verre, S., Structural behaviour of fabric reinforced cementitious matrix (FRCM) strengthened concrete columns under eccentric loading. Composites Part B: Engineering, 2015. 75: p. 235-249.

[7] D’Ambrisi, A., Feo, L. and Focacci, F., Experimental analysis on bond between PBO-FRCM strengthening materials and concrete. Composites Part B: Engineering, 2013. 44(1): p. 524-532.

[8] Kadhim, M.M., Altaee, M.J., Adheem, A.H. and Jawdhari, A.R. A robust 3D finite element model for concrete columns confined by FRCM system. in MATEC Web of Conferences. 2019. EDP Sciences.

[9] Trapko, T., Effect of eccentric compression loading on the strains of FRCM confined concrete columns. Construction and Building Materials, 2014. 61: p. 97-105.

[10] Trapko, T., Confined concrete elements with PBO-FRCM composites. Construction and Building Materials, 2014. 73: p. 332-338.

[11] Kadhim, M., Adheem, A.H. and Altaee, M.J., Shear Strengthening of RC Beams with FRCM Technique. Int. J. Eng. Technol., 2019: p. 169-176.

[12] Alabdulhady, M.Y., Sneed, L.H. and Carloni, C., Torsional behavior of RC beams strengthened with PBO-FRCM composite-an experimental study. Engineering Structures, 2017. 136: p. 393-405.

[13] Gonzalez-Libreros, J., Zanini, M.A., Faleschini, F. and Pellegrino, C., Confinement of low-strength concrete with fiber reinforced cementitious matrix (FRCM) composites. Composites Part B: Engineering, 2019. 177: p. 107407.

[14] ANSYS, Release 17.2 Documentation for ANSYS. Version 17.2, ANSYS Inc., Canonsburg, PA, USA, 2016.

[15] Ghanem, S.Y., Circular RC columns partially confined with FRP. 2016.

[16] Mirmiran, A., Zagers, K. and Yuan, W., Nonlinear finite element modeling of concrete confined by fiber composites. Finite Elements in Analysis and Design, 2000. 35(1): p. 79-96.

[17] ACI-318-14, Building code requirements for reinforced concrete. American Concrete Institute, 2014.

[18] Jawdhari, A.Harik, I., Finite element analysis of RC beams strengthened in flexure with CFRP rod panels. Construction and Building Materials, 2018. 163: p. 751-766.

[19] Kent, D.C.Park, R., Flexural members with confined concrete. Journal of the Structural Division, 1971.

[20] William, K.Warnke, E., Constitutive model for the triaxial behavior of concrete international association for bridge and structure engineering proceedings, 1975, Bergamo.

[21] Altaee MJ., Kadhim M., Altayee S., Adheem A., Employment of damage plasticity constitutive model for concrete members subjected to high strain-rate. IMDC-SDSP EAI. 2020. 